\title{
Persistent Ductus Arteriosus in Ill and Premature Babies
}

\author{
DAVID J. GIRLING* and KATHERINE A. HALLIDIE-SMITH $\dagger$ \\ From the Neonatal Research Unit, Institute of Child Health and Department of Clinical Cardiology, Hammersmith \\ Hospital, London
}

Girling, D. J., and Hallidie-Smith, K. A. (1971). Archives of Disease in Childhood, 46, 177. Persistent ductus arteriosus in ill and premature babies. Thirty-eight ill and premature babies with a diagnosis of persistent ductus arteriosus (PDA) are described. All were patients in the Neonatal Unit of Hammersmith Hospital. 16 of them, who were born during a year in which all babies in the Unit were examined repeatedly and specifically for clinical evidence of PDA, have been compared to a control group in respect of sex, gestational age, weight for dates, birth asphyxia, and respiratory distress.

It is concluded that PDA in this selected group of babies was significantly associated with female sex and respiratory distress but not with gestational age, weight for dates, or birth asphyxia.

Though in these babies clinical evidence of PDA often persisted for several weeks, closure was spontaneous in the great majority.

Five babies developed heart failure and 4 of these responded well to medical treatment. It is suggested that in view of the frequency of spontaneous closure there is no indication to administer oxygen-enriched air to premature babies solely for the purpose of encouraging their ductuses to close.

Anatomical closure of the human ductus arteriosus may occur from a few days to a few months after birth, but occurs by the age of 4 weeks in the great majority of cases (Christie, 1930; Jager and Wollenman, 1942; Mitchell, 1957; Wilson, 1958) and is preceded by functional closure which occurs from a few hours to a few days after birth (Eldridge and Hultgren, 1955; Adams and Lind, 1957; Burnard, 1958, 1959; Braudo and Rowe, 1961; Moss, Emmanouilides and Duffie, 1963). The factors which precipitate closure, or which may delay it, are only partly understood, but prematurity, birth asphyxia, and the respiratory distress syndrome have been thought to delay or prevent it.

Rowe and Lowe (1964) described the murmurs which could be heard in infants with persistent ductus arteriosus (PDA) in most of whom the diagnosis was confirmed by cardiac catheterization or at open operation, and they emphasized that accurate diagnosis in the great majority could be

Received 9 September 1970.

*Percy J. Neate Research Fellow of the Company of Clothworkers. tAssistant Lecturer in Paediatric Cardiology. made on auscultation. Using their clinical criteria we have examined a group of ill and premature babies and have related the clinical diagnosis of PDA to sex, gestational age, birthweight, birth asphyxia, and the occurrence of the respiratory distress syndrome.

\section{Material and Methods}

Thirty-eight babies in whom a diagnosis of PDA was made while they were patients in the Neonatal Unit of this Hospital during the period 1963 to 1969 are reported. Of these 38, 16 have been selected for comparison with a control group. These 16 were all born during the year 1 October 1963 to 30 September 1964, at a gestational age of between 27 and 35 weeks inclusive, and they have been compared in respect of sex, gestational age, weight for dates, birth asphyxia, and respiratory distress to a control group consisting of all other babies admitted on to the Unit during the same year and of the same range of gestational age. The babies admitted on to the Unit that year were selected for comparison, because during that period one of us (K.A.H-S.) examined all the babies on the Unit at least twice a week for clinical evidence of PDA, and these 16 patients are therefore thought to represent a 
fairly complete list of babies of that range of gestational age who developed signs of PDA during that year. The upper limit of gestational age of 35 weeks was chosen because a baby born in this hospital is only certain to be admitted to the Unit where this study was done if its gestational age at birth is $\mathbf{3 5}$ weeks or less.

For the purpose of this study a baby was said to have birth asphyxia if it was apnoeic at the age of 1 minute and was said to have developed the respiratory distress syndrome if at the age of 4 hours it had at least two of the following signs: (a) expiratory grunting, (b) inspiratory recession, or (c) tachypnoea of more than 60 a minute. It was said to be small-for-dates if its birthweight was below the tenth centile for its gestational age on the National Birthday Trust figures supplemented by data from Gruenwald (1966).

All 38 babies were examined at frequent intervals so that accurate information about the duration of their physical signs could be obtained. The diagnosis of PDA was a clinical one, based on the finding of a characteristic murmur in the pulmonary area. Such a murmur could be continuous, crescendo systolic spill- ing into diastole, pansystolic, or ejection systolic in nature. In those infants in whom a continuous murmur was never heard, the diagnosis was assumed if two or more of the other charactistic murmurs were recorded. Clinical closure of the ductus was assumed to have taken place when these specific murmurs finally disappeared. It was thus possible to decide how long the ductus remained clinically patent in each baby and to relate this to its gestational age at birth and postnatal age. In all babies the murmurs were confirmed by phonocardiography.

\section{Results}

Table I shows the sex, gestational age at birth, weight for dates, and incidence of birth asphyxia and respiratory distress in all 38 babies in the study. It also shows which 16 babies were selected for comparison with the control group and the time of onset and duration of the murmur in each baby.

The results of the comparison made between the selected babies and the control group are shown

TABLE I

Clinical Details of all 38 Babies with PDA Showing Ones Selected for Comparison with Control Group

\begin{tabular}{|c|c|c|c|c|c|c|c|c|}
\hline Case No. & Sex & $\begin{array}{c}\text { Gestational } \\
\text { Age } \\
\text { (wk) }\end{array}$ & $\begin{array}{c}\text { Birth } \\
\text { Asphyxia }\end{array}$ & $\begin{array}{l}\text { Respiratory } \\
\text { Distress }\end{array}$ & $\begin{array}{c}\text { Small- } \\
\text { for- } \\
\text { dates }\end{array}$ & $\begin{array}{l}\text { Onset of } \\
\text { Murmur } \\
\text { (wk of life) }\end{array}$ & $\begin{array}{l}\text { Duration } \\
\text { of Murmur } \\
\text { (wk) }\end{array}$ & $\begin{array}{c}\text { Selected } \\
\text { for } \\
\text { Study }\end{array}$ \\
\hline $\begin{array}{r}1 \\
2 \\
3 \\
4 \\
5 \\
6 \\
7 \\
8 \\
9 \\
10 \\
11 \\
12 \\
13 \\
14 \\
15 \\
16 \\
17 \\
18 \\
19 \\
20 \\
21 \\
22 \\
23 \\
24 \\
25 \\
26 \\
27 \\
28 \\
29 \\
30 \\
31 \\
32 \\
33 \\
34 \\
35 \\
36 \\
37 \\
38\end{array}$ & $\begin{array}{l}\text { F } \\
M \\
\text { F } \\
F \\
F \\
M \\
M \\
\text { F } \\
F \\
F \\
F \\
M \\
F \\
M \\
M \\
F \\
M \\
F \\
F \\
F \\
M \\
M \\
F \\
F \\
M \\
F \\
M \\
F \\
F \\
F \\
F \\
F \\
F \\
F \\
F \\
F \\
M \\
F\end{array}$ & $\begin{array}{l}34 \\
35 \\
33 \\
33 \\
33 \\
36 \\
32 \\
28 \\
35 \\
35 \\
33 \\
37 \\
39 \\
35 \\
37 \\
41 \\
31 \\
34 \\
30 \\
32 \\
35 \\
36 \\
30 \\
34 \\
36 \\
40 \\
34 \\
34 \\
31 \\
30 \\
30 \\
29 \\
33 \\
36 \\
34 \\
40 \\
34 \\
39\end{array}$ & $\begin{array}{l}\text { Yes } \\
\bar{Z} \\
\bar{Y} \\
\bar{Z} \\
\bar{Z} \\
\bar{Z} \\
\bar{Z} \\
\text { Yes } \\
\bar{Z} \\
\bar{Z} \\
\overline{\text { Yes }} \\
\bar{Z} \\
\bar{Z} \\
\overline{\text { Yes }} \\
\text { Yes } \\
\bar{Z} \\
\bar{Z} \\
\text { Yes } \\
\bar{Z} \\
\bar{Y} \\
\bar{Z} \\
\bar{Z} \\
\text { Yes }\end{array}$ & $\begin{array}{c}\text { Yes } \\
\text { Yes } \\
\text { Yes } \\
= \\
= \\
\bar{Z} \\
\overline{-} \\
\text { Yes } \\
\overline{-} \\
\text { Yes } \\
\text { Yes } \\
\text { Yes } \\
\text { Yes } \\
\text { Yes } \\
\text { Yes } \\
\overline{-} \\
\bar{Z} \\
\text { Yes } \\
\bar{Y} \\
\text { Yes } \\
\overline{-} \\
\text { Yes } \\
\text { Yes } \\
\text { Yes } \\
\bar{Z} \\
\bar{Z} \\
\bar{Z}\end{array}$ & $\begin{array}{l}\bar{Z} \\
\text { Yes } \\
\text { Yes } \\
\overline{-} \\
\bar{Z} \\
\overline{-} \\
\text { Yes } \\
\overline{-} \\
\text { Yes } \\
\text { Yes } \\
\text { Yes } \\
\text { Yes } \\
\bar{Z} \\
\bar{Z} \\
\overline{-} \\
\text { Yes } \\
\overline{-} \\
\text { Yes } \\
\text { Yes } \\
\text { Yes } \\
\text { Yes } \\
\text { Yes } \\
\text { Z } \\
\bar{Z} \\
\overline{\text { Yes }} \\
\text { Yes } \\
\text { Yes } \\
\text { Yes } \\
-\end{array}$ & $\begin{array}{c}1 \\
\text { NK } \\
1 \\
2 \\
1 \\
\mathrm{NK} \\
3 \\
2 \\
1 \\
3 \\
2 \\
1 \\
\mathrm{NK} \\
1 \\
1 \\
2 \\
\mathrm{NK} \\
2 \\
2 \\
1 \\
\mathrm{NK} \\
2 \\
8 \\
1 \\
4 \\
5 \\
5 \\
6 \\
3 \\
4 \\
4 \\
2 \\
1 \\
1 \\
4 \\
1 \\
2 \\
5\end{array}$ & $\begin{array}{c}3 \\
\text { NK } \\
3 \\
9 \\
3 \\
\text { NK } \\
2 \\
3 \\
3 \\
1 \\
7 \\
9 \\
\text { NK } \\
2 \\
1 \\
4 \\
\text { NK } \\
1 \\
7 \\
12 \\
\text { NK } \\
6 \\
2 \\
9 \\
4 \\
1 \\
11 \\
10 \\
2 \\
3 \\
4 \\
3 \\
7 \\
\text { Still present } \\
3 \\
9 \\
5 \\
\text { Still present }\end{array}$ & 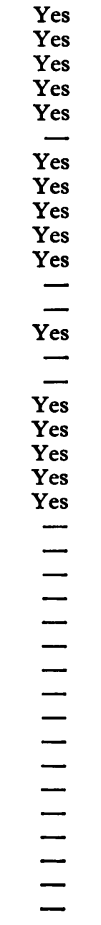 \\
\hline
\end{tabular}


in Tables II and III. In Table II the babies are split into three groups according to gestational age. The first group (gestational ages 27-29 weeks inclusive) is too small for statistical evaluation. There is no significant difference between the incidences of PDA in the other two groups $\left(x^{2}=\right.$ $0.66, P>0.4)$. There is therefore no evidence that gestational age over the stated range is significantly related to the persistence of ductus arteriosus.

TABLE II

Babies with PDA and Control Babies Grouped According to Gestational Age

\begin{tabular}{l|ccc|c}
\hline & \multicolumn{3}{|c|}{ Gestational Age (wk) } & \multirow{2}{*}{ Total } \\
\cline { 2 - 4 } & $27-29$ & $30-32$ & $33-35$ & \\
\hline Babies with PDA & 1 & 4 & 11 & 16 \\
Babies without PDA & 11 & 22 & 36 & 69 \\
\hline
\end{tabular}

In Table III the 16 babies with PDA and the 69 in the control group are divided up according to sex, weight for dates, birth asphyxia, and respiratory distress. There is no significant difference between the two groups in respect of weight for dates $\left(x^{2}=0.35, P>0.5\right)$ or of the occurrence of birth asphyxia $\left(\chi^{2}=2 \cdot 41, \mathrm{P}>0 \cdot 1\right)$, though it is interesting to note that a larger proportion of babies in the control group had birth asphyxia than in the group with PDA. The PDA group differed significantly from the control group in having a higher proportion of girls $\left(\chi^{2}=4 \cdot 15, P<0.05\right)$ and of babies who had had respiratory distress $\left(x^{2}=5 \cdot 45\right.$, $\mathrm{P}<0 \cdot 025$ ).

In only two babies was the murmur present at birth. In the majority it appeared, as can be seen from Table I, during the first two weeks of life though in a few it appeared much later than this, in the sixth, seventh, or even eighth week. In spite of the very long duration of patency in this group closure was spontaneous in the great majority and in 2 babies ( 27 and 28 ) did not occur until the age of 16 weeks.

The time of clinical closure of the ductus was known in 33 of the 38 babies. The mean time to clinical closure was 49 days with a range of 11 to 112 days, and bore no significant relation to the estimated date of delivery. Two patients (Cases 34 and 38) still have clinical evidence of PDA at the ages of 4 years and 1 year respectively.

Cases 8, 12, 20,35, and 36 developed signs of heart failure. In Case 12, birthweight only $1810 \mathrm{~g}$, this proved intractable and death was the result of heart failure; a murmur was still present at the time of death and there was a widely patent ductus at necropsy and no other cardiovascular abnormality. All the babies who developed heart failure with the exception of Case 12 had a good response to digoxin and mersalyl, and their ductuses all closed spontaneously.

Case 16 also died, during the period of the study, of bronchopneumonia at the age of 9 weeks. There was no murmur at the time of death and at necropsy the ductus was found to be closed.

\section{Discussion}

There is evidence about the time of closure of the ductus arteriosus in the full-term infant from clinical observations, post-mortem studies, and animal experiments. The observations of Eldridge and Hultgren (1955), Adams and Lind (1957), Burnard (1958, 1959), Braudo and Rowe (1961), and Moss et al. (1963) have shown that in normal full-term infants shunting through the ductus arteriosus is often present shortly after birth but that by the age of about 15 hours it is insignificant or has ceased altogether, though it may occasionally persist for longer (e.g. up to a week after birth) with subsequent spontaneous closure.

These observations are supported by the postmortem findings of Christie (1930), Jager and Wollenman (1952), Mitchell (1957), and Wilson (1958). By the end of the first week of life a normally closing ductus will just admit a $2 \mathrm{~mm}$ probe, and by the end of the third week is likely to be completely closed, though it must be emphasized that functional closure before death is not synonymous with anatomical obliteration found at

TABLE III

Babies with PDA and Control Babies Grouped According to Sex, Weight for Dates, Birth Asphyxia, and Respiratory Distress

\begin{tabular}{|c|c|c|c|c|c|c|c|}
\hline & & Male & Female & $\begin{array}{c}\text { Small } \\
\text { for Dates }\end{array}$ & $\begin{array}{c}\text { Birth } \\
\text { Asphyxia }\end{array}$ & $\begin{array}{l}\text { Respiratory } \\
\text { Distress }\end{array}$ & Total \\
\hline $\begin{array}{l}\text { Babies with PDA } \\
\text { Babies without PDA }\end{array}$ & & $\begin{array}{r}5 \\
41\end{array}$ & $\begin{array}{l}11 \\
28\end{array}$ & $\begin{array}{l}3 \\
9\end{array}$ & $\begin{array}{r}2 \\
22\end{array}$ & $\begin{array}{r}9 \\
18\end{array}$ & $\begin{array}{l}16 \\
69\end{array}$ \\
\hline
\end{tabular}


necropsy. We have found no reports of a postmortem study relating patency of the ductus arteriosus to the gestational age at the time of death.

In the field of animal experiments the rapid functional closure of the ductus after birth has been well documented in the lamb (Born et al., 1956; Dawes, 1961), the puppy (Handler, 1956), the guinea-pig (Record and McKeown, 1955), and in several other species (Gillman and Burton, 1966), with very few species differences. This work supports the generally accepted view that in the normal full-term infant functional closure of the ductus occurs within a few hours of birth and anatomical obliteration during the first few weeks of life.

Very few reports have appeared on the behaviour of the ductus in premature babies. Powell (1963) reported six premature babies with PDA and found that spontaneous closure occurred in 5 , in 4 of these approximately at the time of their expected dates of delivery. In 1966 Danilowicz, Rudolph, and Hoffman described 5 premature babies with delayed closure, and Auld (1966) reported the delayed closure of the ductus in 7 premature infants with the respiratory distress syndrome. There was therefore already some indication that the behaviour of the ductus arteriosus in ill and premature babies might be different from that in the normal full-term baby. The present study shows how long the ductus may remain patent in the premature baby and still close spontaneously.

Both birth asphyxia and respiratory distress produce hypoxia and might be expected to influence the closing of the ductus. The importance of arterial oxygen tension in influencing closure of the ductus is already well known (Born et al., 1956; Dawes, 1961; Kovalčík, 1963; Moss et al., 1964; Rowe and Lowe, 1964; Gillman and Burton, 1966), and Record and McKeown (1953) have already reported a high incidence of birth asphyxia in a retrospective study of older children in whom patency of the ductus had persisted. In spite of this, the occurrence of birth asphyxia, at least as defined for this study, was found to be associated with closure of the ductus rather than patency, though this effect was not statistically significant in this number of babies. There is at least some animal work to suggest that birth asphyxia might actually favour closure of the ductus. Born et al. (1956) found that the ductus often became constricted in asphyxiated lambs, and they suggested that this might be due to the release of sympathomimetic amines. If hypoxia is a cause of delayed closure in premature babies, it seems that the prolonged hypoxia of respiratory distress is more important in this respect than is the fleeting hypoxia of birth asphyxia.

Premature infants with PDA may develop heart failure. Even if this occurs their ductuses are still likely to close spontaneously. This has already been reported by Auld (1966) and Danilowicz et al. (1966), and is confirmed by our own findings. It has been suggested that the administration of oxygen to babies with PDA might encourage their ductuses to close (Powell, 1963), but in view of the known dangers to the eyes and probable dangers to the lungs of exposing premature babies to high concentrations of oxygen, and because closure of the ductus occurs spontaneously in the great majority, we consider that PDA, with or without heart failure, is not an indication on its own for the administration of enriched oxygen mixtures.

We should like to thank Professor J. P. M. Tizard for his help in the preparation of this paper. The necropsies were performed by Dr. J. S. Wigglesworth.

\section{REFERENCES}

Adams, F. H., and Lind, J. (1957). Physiologic studies on the cardiovascular status of normal newborn infants (with special reference to the ductus arteriosus). Pediatrics, 19, 431.

Auld, P. A. M. (1966). Delayed closure of the ductus arteriosus. fournal of Pediatrics, 69, 61 .

Born, G. V. R., Dawes, G. S., Mott, J. C., and Rennick, B. R. (1956) The constriction of the ductus arteriosus caused by oxygen and by asphyxia in newborn lambs. Fournal of Physiology, 132, 304.

Braudo, M., and Rowe, R. D. (1961) Auscultation of the heart: early neonatal period. American fournal of Diseases of Children, 101, 575.

Burnard, E. D. (1958). A murmur from the ductus arteriosus in the newborn baby. British Medical fournal, 1, 806.

Burnard, E. D. (1959). A murmur that may arise from the ductus arteriosus in the human baby. Proceedings of the Royal Society of Medicine, 52, 77.

Christie, A. (1930). Normal closing time of the foramen ovale and the ductus arteriosus. American fournal of Diseases of Children, 40, 323.

Danilowicz, D., Rudolph, A. M., and Hoffman, J. I. E. (1966). Delayed closure of the ductus arteriosus in premature infants. Pediatrics, 37, 74.

Dawes, G. S. (1961). Changes in the circulation at birth. British Medical Bulletin, 17, 148.

Eldridge, F. L., and Hultgren, H. N. (1955). The physiologic closure of the ductus arteriosus in the newborn infant. fournal of Clinical Investigation, 34, 987.

Gillman, R. G., and Burton, A. C. (1966). Constriction of the neonatal aorta by raised oxygen tension. Circulation Research, 19, 755.

Gruenwald, P. (1966). Growth of the human fetus. American fournal of Obstetrics and Gynecology, 94, 1112.

Handler, J. J. (1956). The foetal circulation and its changes at birth in some small laboratory animals. Fournal of Physiology, 133, 202.

Jager, B. V., and Wollenman, O. J., Jr. (1942). An anatomical study of the closure of the ductus arteriosus. American fournal of Pathology, 18, 595.

Kovalikik, V. (1963). The response of the isolated ductus arteriosus to oxygen and anoxia. Fournal of Physiology, 169, 185.

Mitchell, S. C. (1957). The ductus arteriosus in the neonatal period. Fournal of Pediatrics, 51, 12. 
Moss, A. J., Emmanouilides, G. C., and Duffie, E. R., Jr. (1963). Closure of the ductus arteriosus in the newborn infant. Pediatrics, 32, 25.

Moss, A. J., Emmanouilides, G. C., Adams, F. H., and Chuang, K. (1964). Response of ductus arteriosus and pulmonary and systemic arterial pressure to changes in oxygen environment in newborn infants. Pediatrics, 33, 937.

Powell, M. L. (1963). Patent ductus arteriosus in premature infants. Medical fournal of Australia, 2, 58.

Record, R. G., and McKeown, T. (1953). Observations relating to the aetiology of patent ductus arteriosus. British Heart Fournal, 15, 376.

Record, R. G., and McKeown, T. (1955). The effect of reduced atmospheric pressure on closure of the ductus arteriosus in the guinea pig. Clinical Science, 14, 225.

Rowe, R. D., and Lowe, J. B. (1964). Auscultation in the diagnosis of persistent ductus arteriosus in infancy: a study of 50 patients. New Zealand Medical fournal, 63, 195.

Wilson, R. R. (1958). Post-mortem observations on contraction of the human ductus arteriosus. British Medical fournal, 1, 810.

Correspondence to Dr. D. J. Girling, Department of Child Health, Hammersmith Hospital, Du Cane Road, London W.12. 